\title{
Development on Glass Formulation for Aluminum Metal and Glass Fiber
}

\section{유리섬유 및 알루미늄 금속 혼합물 유리조성 개발}

Hyun-Je Cho* and Cheon-Woo Kim

KHNP Central Research Institute, 1312-70 Yuseong-daero, Yuseong-gu, Daejeon, Korea

조현제*, 김천우

한수원중앙연구원, 대전시 유성구 유성대로 1312번길 70

(Received August 16, 2012 / Revised October 24, 2012 / Approved November 05, 2012)

Vitrification technology has been widely applied as one of effective processing methods for wastes generated in nuclear power plants. The advantage of vitrifying for low- and intermediate-level radioactive wastes has a large volume reduction and good durability for the final products. Recently, a filter using on HVAC(Heating Ventilating \& Air Conditioning System) is composed with media (glass fiber) and separator (aluminum film) has been studied the proper treatment technology for meeting the waste disposal requirement. Present paper is a feasibility study for the filter vitrification that developing of the glass compositions for filter melting and melting test for physicochemical characteristic evaluation. The aluminum metal of film type is preparing with $0.5 \mathrm{~cm}$ size for proper mixing with glass frit, glass fiber is also preparing with $1 \mathrm{~cm}$ size within crucible. The glass compositions should be developed considering molten glass are related with wastes reduction. Glass compositions obtained from developing on glass formulation are mainly composed of $\mathrm{SiO}_{2}$ and $\mathrm{B}_{2} \mathrm{O}_{3}$ for aluminum metal. A variety of factors obtained from the glass formulation and melting test are reviewed, which is feeding rate and glass characteristics of final products such as durability for implementing the wastes disposal requirement.

Key words: Vitrification, Glass formulation, Aluminum metal, Glass fiber

원전에서 발생되는 방사성폐기물에 대한 고화처리 방법 중 하나인 유리화기술이 일부 가연성폐기물에 대해 적용되고 있다. 국내외적으로 중저준위 방사성폐기물의 효과적인 감용과 안정적인 처분을 위해 다양한 폐기물에 대한 유리화기술 적용방안 이 확대 연구되고 있으며, 최근에는 가연성폐기물 뿐만 아니라 알루미늄 금속과 같은 비가연성폐기물에도 유리화 연구가 활 발하게 진행되고 있다. 공기조화계통 (HVAC)에는 주로 필터가 이용되고 있으며, 사용 후 필터는 여과재 (유리섬유 및 알루미 늄)를 이용하여 배기체를 흡착하기 때문에 방사성폐기물로 처리가 되어야 한다. 본 연구는 필터에 대한 처리기술 연구를 위 해 유도가열식 저온용융로 (Cold Crucible Induction Melter: CCIM)를 이용한 유리화 타당성 연구를 수행하였다. 사용후 필 터에 대한 유리화 (Vitrification)는 먼저 유리섬유 및 알루미늄 함량을 고려한 최적의 유리조성을 개발 하였으며, 개발된 유리 조성을 이용하여 최적의 폐기물 저감을 위한 용융변수와 최종 생성된 유리고화체의 특성을 분석하였다. 사용후 필터 유리화 용 조성유리는 주로 $\mathrm{SiO}_{2}$ 와 $\mathrm{B}_{2} \mathrm{O}_{3}$ 로 구성되어 있다. 전기로를 이용한 용융물 특성시험에서는 폐기물 투입률 및 최종 생성물인 유리고화체의 특성이 검토되었다. 본 연구에서는 알루미늄 금속과 유리섬유로 구성된 필터에 대한 유리조성 개발과 이를 통 해 생성된 유리고화체의 물리화학적 특성을 검토하고 유리화 타당성을 확인하였다.

중심단어 : 유리화, 유리조성, 알루미늄 금속 폐기물, 사용 후 필터 폐기물

*Corresponding Author . E-mail :cho@khnp.co.kr, Tel: +82.42.870.5445 


\section{1. 서 론}

최근 원전발생 방사성폐기물의 부피를 감소시키면서 처 분 요건을 충족할 수 있는 고화처리 기술의 일환으로 유도 가열식 저온용융로 (Cold Crucible Induction Melter: CCIM) 및 플라즈마토치용융로 (Plasma Torch Melter: PTM)를 이 용한 유리화 (Vitrification) 연구가 활발하게 진행되고 있다. 미국, 프랑스 등은 고준위폐기물에 대한 유리화 공정기술 개발을 위한 유리화 상용설비를 운영하고 있으며, 방사성폐 기물에 대한 유리조성 개발 및 용융특성 연구 등에 다양하 게 활용 하고 있다 $[1,2]$. 일본은 고준위폐기물에 대한 고화 기술 방안으로 세라믹용융로를 이용한 폐기물 용융특성 연 구를 수행하고 있다 [3]. 그러나 세라믹용융로의 배출시스템 에서 금속 및 결정체에 의한 막힘 현상 등이 발생하여 현재 실증연구가 중단된 상태이며, 최근에는 용융로 건전성 유지 와 용융물의 원활한 배출을 위해 CCIM을 이용한 가연성 및 비가연성 폐기물 용융 연구방안을 검토하고 있다. 한국수 력원자력(주)은 2009년부터 울진원전에 유리화 상용설비 (Ulchin Vitrification Facility: UVF)를 운영하고 있으며, 상 기 설비를 통해 가연성잡고체 및 폐수지를 처리하고 있으 며, 한국수력원자력 중앙연구원에 구축된 CCIM 및 PTM 실 증설비를 통해 가연성 및 비가연성 폐기물에 대한 유리화 연구를 수행하고 있다.

원전 발생 중 - 저준위 방사성폐기물 (Low-and Intermediate-Level Radioactive Waste : LILW) 중에는 작업종사자 가 사용한 작업복, 제염지 등의 가연성잡고체 (Dry Active Waste : DAW)가 대부분을 차지하고 있으며, 액체처리계 통에서 발생된 저방사성폐수지 (Spent Resin)와 농축폐액 (Concentrated Boric Acid) 및 공기조화계통에서 발생된 사 용 후 필터 등이 있다. 일반적으로 필터는 압축하여 드럼 포 장으로 관리하고 있으나, 드럼내 알루미늄 금속에 의한 발 화 가능성이 있어 필터 여과재에 대한 고화처리 연구가 검 토되고 있다. 미국, 일본 등은 사용 후 필터를 폐기물 조밀 성을 위해 압축하여 드럼에 포집 하거나 첨가제 (Additive) 를 활용하여 고화 - 처리하고 있으나 처분요건을 만족하지 못하는 것으로 평가되었다[4]. 원전의 공기조화계통에서 발 생되는 사용 후 필터는 여과재(유리섬유)와 separator (알 루미늄 금속)로 구성되어 있으며, 이들은 배기체를 흡착하 기 때문에 방사성폐기물로 관리 운영되고 있다. 사용 후 필 터를 유리화 할 경우 방사성물질을 유리 구조속에 안정적으 로 가두기 위해서는 유리섬유 및 알루미늄 금속에 대한 용 융 거동특성이 분석되어야 한다.

폐기물을 유리화하기 위해서는 먼저 폐기물 특성이 분석
되어야 하며, 이를 통해 폐기물 투입률(Waste Loading)을 최적 상태로 유지하기 위한 첨가유리 (Base Glass)로써 유 리프릿이 결정된다. 유리프릿은 폐기물과 함께 투입되어 유 리고화체를 형성하며, 고화체의 물리화학적 특성을 최적화 하여 개발되는 것이 후보유리인 유리조성체가 된다. 유리 화에서 대상폐기물에 대한 최종 유리조성 (Glass Formulation) 개발은 폐기물 투입률과 관련하여 개발되는 후보유리 (frit) 선정, 이들 첨가유리에 대한 실험적 유리제조 및 물리 화학적 특성 평가, 유리화 실증시험(Demonstration Test) 단계를 거쳐 유리조성체가 결정된다. 유리화를 위한 후보 유리 개발에 있어서, 폐기물에 함유된 무기물 함량에 따라 유리특성이 달라지는데, 이들 함량 분포는 점도 및 전기전 도도 등의 용융 변수에도 영향을 주게 된다. 실증시험을 통 해서는 개발된 유리조성의 품질과 배기체 특성 분포를 얻게 되며 폐기물 투입률을 통해 유리에 용융될 폐기물의 감용비 (Reduction Factor)를 확인하게 된다. 생성된 최종유리 고 화체의 압축강도 및 침출특성으로부터 폐기물 처분요건 충 족여부를 평가하게 된다[5,6].

CCIM을 이용한 유리화에서는 폐기물을 최적으로 용융시 키기 위한 조성유리 개발과 용융로 건전성을 유지하기 위 한 적절한 점도 및 전기전도도 등의 운전인자 확보가 필요 하다. 개발되는 유리의 특성은 유리 구성성분에 얼마만큼의 무기물을 투입 (Waste Loading) 하느냐에 따라 달라진다. 유리조성 개발에서 컴퓨터 코드에 입력하는 주요인자로는 산화물 조성비와 폐기물 투입률 등이며, CCIM 운전온도인 $1,150^{\circ} \mathrm{C}$ 에서의 점도 (Viscosity) 범위인 10 100 poise 및 전기전도도 (Electric Conductivity) 범위인 0.1 1.0 S/cm 유지하기 위한 용융 운전조건 개발과 상 안정성 등 화학적 으로 안정한 유리고화체 (Candidate Glass) 개발로 나누어 진다. 이와 같은 평가를 통해 대상폐기물의 적절한 감용비 를 도출함으로써 유리화 시 최적의 폐기물 투입량을 얻게 된다. 유리고화체의 품질 측면에서 화학적 견고성을 확인 하기 위해 수행하는 침출시험 (Product Consistency Test, ASTM C1285-02 : PCT)을 통해 기준 원소(B, Na, Li, Si 등) 에 대한 유리고화체의 침출률이 기준유리 (Savannah River Laboratory-Environmental Assessment : SRL-EA)의 침출기 준을 만족하는지 확인하게 된다.

유리고화체는 용융로내 용탕을 제조·유지하며 폐기물을 용융 시키는 역할을 한다. 첨가유리(Base Glass)는 폐기물 과 함께 투입되는 유리로 사용되는데, 유리용탕에 용융될 때 폐기물 성분에 따라 용탕의 점도와 전기전도도 등의 운 전변수가 변하기 때문에 이를 일정하게 유지시키기 위한 첨 가물로서의 역할을 하는 유리를 의미한다. 첨가유리 및 유 
리고화체가 적합한지 아닌지에 대한 판단 기준은 다음과 같 다. 용융상태의 유리 점도기준 유지, 용융 유리의 전기전도 도 기준 유지, 유리고화체의 침출률이 미국 표준유리 이하 만족, 고화체 내 폐기물 성분 함량이 감용비 측면에서의 적 정값 유지 등이 있다. 용융상태에서 유리의 점도가 낮을 경 우 용융 유리에 의한 접촉물체들의 부식이 초래될 뿐만 아 니라 내침출성이 낮아지게 되고, 점도가 높을 경우에는 유 리와 폐기물간의 혼합이 용이하지 못하고 폐기물의 처리 용량도 떨어지게 된다. 유리조성 개발에서는 폐기물의 처 리량을 높이기 위해 유리조성체의 점도 요건을 완화하여 개발하게 되며, 전기전도도는 유리 용융시 유도전류 가열 식 용융로에 안정적인 주울효과 (Joule's effect)를 발휘할 수 있는 요인이 된다. 일반적으로 용융 유리가 전기전도도 의 적정 범위를 벗어날 경우 안정적인 폐기물 용융 상태를 유지하기 위한 고주파발진기(High Frequence Generator : $\mathrm{HFG)}$ 의 운전에 영향을 미치게 된다. 점도와 전기전도도는 유리용탕과 폐기물을 안정적으로 혼합 및 용융을 유지하게 할 뿐만 아니라 고품질의 최종 유리고화체를 만들 수 있는 주요 요인이 된다. 본 연구는 유리섬유 및 알루미늄 금속 을 유리화하기 위한 유리를 개발하고, 전기로를 이용한 용 융물 특성 및 생성 유리의 특성분석 등을 통해 유리화 타당 성을 도출하는데 목적이 있다.

\section{2. 실험방법}

\section{1 폐기물 조성 및 유리고화체 특성}

폐기물 유리조성 개발을 위해 원전에 사용중인 필터의 조 성(산화물 분포)을 분석하였다. 일반적으로 HVAC에 사용 되는 필터는 HEPA와 medium 두 종류이며, medium 필터 의 경우 유리섬유와 알루미늄의 무게는 평균 $1.8 \mathrm{~kg}$ 과 $1.7 \mathrm{~kg}$ 으로서 폐기물 중량비를 고려할 때 약 1:1정도이며, HEPA 의 경우 유리섬유 $2.9 \mathrm{~kg}$ 과 알루미늄 $4.1 \mathrm{~kg}$ 정도로 무게비 1:1.4 정도로 구성되어 있다. 이들 필터내 유리섬유에 대한 분석결과 Medium의 경우 산화물 함량은 $77.5 \%, \mathrm{HEPA}$ 의 경우 $81.3 \%$ 정도 분포하였다. Table 1은 각 필터의 유리섬 유에 대한 산화물 분포 및 두 필터의 유리섬유를 혼합한 경 우의 평균 산화물 분포를 보여주고 있다. 폐기물 전처리 및 CCIM에 투입시 필터내 유리섬유가 1:1로 혼합된다고 가정 할 때, 미네랄 함량은 $81.3 \%$ 를 차지하게 된다.

본 연구에 사용된 대상폐기물은 원전 HVAC 발생 필터를 기준으로 유리섬유와 알루미늄이 평균 중량비 1 대 1.2 로 구성되어 있으며, 산화물 분포로는 대부분 $\mathrm{Al}_{2} \mathrm{O}_{3}$ 가 $65 \mathrm{wt} \%$
이상, $\mathrm{SiO}_{2}$ 가 $20 \mathrm{wt} \%$ 내외, 기타 $\mathrm{B}_{2} \mathrm{O}_{3}$ 및 $\mathrm{Na}_{2} \mathrm{O}$ 가 수 $\mathrm{wt} \%$ 정도 함유되어 있다. Table 2 는 유리섬유와 알루미늄 함량 을 고려한 폐필터의 산화물 분포를 보여주고 있다. 필터에 대한 유리조성 개발에서는 혼합폐기물의 무기산화물 함량 을 고려하였고, 전처리에 따라 알루미늄의 분포함량이 최 대 $\pm 10 \mathrm{wt} \%$ 까지 변한다고 가정하여 함량변화 여유도를 주면서 유리프릿을 개발하였다. Table 2에서 Mixing(A)는 $\mathrm{HEPA}$ 와 medium이 1:1 혼합된 상태의 산화물 분포를 나타 내며, 이중에서 알루미늄의 함량은 약 $70 \%$ 를 차지하고 있 다. Mixing(B)는 혼합시료중 $\mathrm{Al}$ 함유가 $\operatorname{Mixing}(\mathrm{A})$ 에 비해 $10 \%$ 적은 경우이며 Mixing(C)는 $\mathrm{Al}$ 함유가 $10 \%$ 많게 혼합 된 경우인데, 이것은 필터의 전처리 과정을 통해 유리섬유 와 알루미늄이 혼합될 때 알루미늄의 함유량 변동 가능성을 고려한 것이다. 알루미늄 함유량 변동을 보면 $\mathrm{Al}_{2} \mathrm{O}_{3}$ 는 59에 서 $71 \mathrm{wt} \%$ 의 분포를 보여주기 때문에 필터를 전처리 할 경 우 많은 양의 알루미늄이 혼합될 경우를 가정한 것이다.

용융에 사용된 붕규산 유리프릿 조성은 폐기물내 대부분을 차지하고 있는 알루미늄이 산화물 $\left(\mathrm{Al}_{2} \mathrm{O}_{3}\right)$ 형태로 용해되도 록 $\mathrm{SiO}_{2}+\mathrm{B}_{2} \mathrm{O}_{3}$ 의 함량이 절반 이상 되도록 하였으며 여기에 $\mathrm{Na}_{2} \mathrm{O}$ 를 추가하여 유리프릿을 개발하였다. 보통 알루미늄 금 속에 산소를 퍼징(purging) 해주면 $2 \mathrm{Al}$ (solid) $+\frac{3}{2} \mathrm{O}_{2}$ (gas) $\rightarrow$ $\mathrm{Al}_{2} \mathrm{O}_{3}$ (glass)와 같은 화학식에 의해 $\mathrm{Al}$ 금속이 산화물로 변경 되어 유리 matrix로 전환된다. 필터에 대한 유리조성 개발에 서는 알루미늄을 CCIM으로 용융할 경우와, 유리섬유 및 알루 미늄이 혼합된 채 용융할 경우를 고려하여 개발하였다. 먼저 알루미늄을 단독으로 용융하기 위해 컴퓨터프로그램을 이용 하여 분석한 결과 일정량의 첨가제가 필요한 것으로 나타났 다. 알루미늄 금속을 적절하게 용융하기 위해 필요한 산화물

Table 1. Distribution of Oxide Composition (wt\%) for Glass Fiber.

\begin{tabular}{cccc}
\hline Oxide & HEPA & Medium & Mixing \\
\hline $\mathrm{Al}_{2} \mathrm{O}_{3}$ & 7.8 & 10.2 & 9.4 \\
\hline $\mathrm{B}_{2} \mathrm{O}_{3}$ & 9.9 & 7.2 & 8.2 \\
\hline $\mathrm{Na}_{2} \mathrm{O}$ & 12.7 & 10.1 & 11.0 \\
\hline $\mathrm{SiO}_{2}$ & 57.2 & 54.7 & 55.6 \\
\hline Others & 12.4 & 17.8 & 15.8 \\
\hline
\end{tabular}

Table 2. Distribution of Oxide Composition (wt\%) Mixed Glass Fiber and Al.

\begin{tabular}{cccc}
\hline Oxide & Mixing $(\mathrm{A})$ & Mixing $(\mathrm{B})$ & Mixing $(\mathrm{C})$ \\
\hline $\mathrm{Al}_{2} \mathrm{O}_{3}$ & 67.4 & 59.4 & 71.3 \\
\hline $\mathrm{B}_{2} \mathrm{O}_{3}$ & 2.4 & 2.5 & 2.8 \\
\hline $\mathrm{Na}_{2} \mathrm{O}$ & 3.2 & 3.3 & 3.5 \\
\hline $\mathrm{SiO}_{2}$ & 16.2 & 16.8 & 17.1 \\
\hline Others & 10.8 & 18 & 5.3 \\
\hline
\end{tabular}


분포는 알루미늄 투입량에 따라 달라지며, 알루미늄 투입 량을 총 산화물의 20 35 wt\% 고려할 경우 필요한 유리프 릿의 함량은 $\mathrm{SiO}_{2}$ 가 $37 \sim 43 \%, \mathrm{Na}_{2} \mathrm{O}$ 이 $21 \sim 26 \%, \mathrm{~B}_{2} \mathrm{O}_{3}$ 이 $27 \sim 30 \%$ 일 때 용융 최적 조건인 점도 100 poise 이하 및 전기전도도 $0.5 \mathrm{~S} / \mathrm{m}$ 이하로 나타났다. 컴퓨터 코드를 이 용한 용융조건 분석결과, 투입되는 알루미늄 폐기물 함량 이 많을수록 붕규산 함량이 낮게 분포되어 점도 및 전기전 도도가 운전범위를 벗어나는 것으로 나타났다. 따라서 알 루미늄 폐기물 함량을 적절하게 유지하면서 용융 운전변 수가 최적이 되도록 고려하였다. 알루미늄만 용융할 경우, 알루미늄 투입량은 $30 \mathrm{wt} \%$ 이하로 유지하여야 하며, 최종 유리고화체의 특성분석 결과 고점도를 보여주고 있으며, 침출률은 일부원소에서 기준값을 상회하는 것으로 나타났 다. 따라서 조성유리에 혼합되는 알루미늄 폐기물 투입률 을 낮게 유지한다고 하더라도 용융물의 점도와 전기전도 도가 높기 때문에 알루미늄 단독 유리화는 양호하지 않음 을 확인하였다.

Table 3은 Table 2의 유리섬유와 알루미늄이 혼합된 폐기 물로부터 개발된 유리고화체의 물성 특성을 분석한 것이다. 혼합 필터 폐기물 투입량을 $45 \mathrm{wt} \%, 40 \mathrm{wt} \%$ 및 $35 \mathrm{wt} \%$ 와 같 이 달리하여 투입량에 대한 유리고화체의 점도, 전기전도도, 밀도 등의 특성을 분석한 결과, 폐기물 투입량을 $45 \mathrm{wt} \%$ 이 상일 경우 점도와 전기전도도는 기준치 이상으로 나타났고 PCT 침출률 값도 높게 나타났다. 따라서 낮은 점도와 적절한 전기전도도를 유지하기 위해서는 폐기물 투입량이 $40 \mathrm{wt} \%$ 이내가 적절한 것으로 나타났다. 이 경우 점도는 알루미늄 혼 합이 평균 (Mixing A)보다 많이 함유된 필터 C에서 높게 나타 났으며 Mixing(B)는 낮게 분포함을 확인 하였다. 따라서 필 터를 용융할 경우 알루미늄 함량에 따라 점도가 비례하기 때 문에 적절한 알루미늄 금속이 혼합 될 수 있도록 폐기물 전처 리 시 고려할 필요가 있다.

Table 3. Physicochemical Properties of Candidate Glass for Filter(glass fiber and aluminum).

\begin{tabular}{|c|c|c|c|c|}
\hline \multicolumn{2}{|c|}{ Items } & $\begin{array}{c}\mathrm{WL}^{1)} \\
45 \mathrm{wt} \%\end{array}$ & $\begin{array}{c}\mathrm{WL} \\
40 \mathrm{wt} \%\end{array}$ & $\begin{array}{c}\mathrm{WL} \\
35 \mathrm{wt} \%\end{array}$ \\
\hline \multirow{4}{*}{$\begin{array}{l}\text { 7-Day PCT } \\
\left(\mathrm{g} / \mathrm{m}^{2}\right)\end{array}$} & B & $1.3 \sim 4.3$ & $1.4 \sim 2.8$ & $0.5 \sim 1.5$ \\
\hline & $\mathrm{Li}$ & $0.3 \sim 1.5$ & $0.3 \sim 1.3$ & $0.3 \sim 1.4$ \\
\hline & $\mathrm{Na}$ & $0.2 \sim 1.8$ & $0.2 \sim 1.6$ & $0.2 \sim 1.4$ \\
\hline & $\mathrm{Si}$ & $\sim 0.3$ & $\sim 0.2$ & $\sim 0.1$ \\
\hline \multicolumn{2}{|c|}{ Viscosity (poise) ${ }^{\dagger}$} & $\sim 91$ & $\sim 48$ & $\sim 15$ \\
\hline \multicolumn{2}{|c|}{ Conductivity $(\mathrm{S} / \mathrm{cm})^{\dagger}$} & $\sim 0.63$ & $\sim 0.52$ & $\sim 0.46$ \\
\hline \multicolumn{2}{|c|}{ Density $\left(\mathrm{g} / \mathrm{cm}^{3}\right)$} & $2.7 \sim 2.9$ & $2.6 \sim 2.8$ & $2.6 \sim 2.7$ \\
\hline
\end{tabular}

\section{2 폐기물 점도}

유리조성 프로그램을 이용하여 개발한 필터의 첨가유리 는 용융로 운전변수(점도, 전기전도도 등)를 적절히 유지시 키며 최종 배출 (pouring)시 안정적으로 배출할 수 있게 개 발되어야 한다. 사용된 시료는 알루미늄 단독으로 처리할 경우와 유리섬유에 혼합하는 경우를 고려하여 개발하였으 며, 점도측정을 위해 독일 HAKKE사의 점도 측정계 (RotoVisco RV2)를 사용하여 $950 \sim 1,250^{\circ} \mathrm{C}$ 에서 측정하였다. 직 경 $23 \mathrm{~mm}$ 유리를 Pt-20\%/Rh crucible에 넣고 점도를 측정하 고자 하는 온도에서 직경 $9 \mathrm{~mm} \mathrm{Pt-20 \% /Rh} \mathrm{spindle을} \mathrm{용융유}$ 리에 넣고 측정하였다. 점도 보정을 위하여 $1,000 \sim 1,450^{\circ} \mathrm{C}$ 온도범위에서 표준유리 (German Society of Glass Technology)를 사용하였다. 측정값은 Vogel-Fulcher-Tammann 식 $\ln n=\mathrm{A} /\left(\mathrm{T}-\mathrm{T}_{0}\right)+\mathrm{B}$ 을 이용하여 유리의 점도 측정값을 환산하 였다.

개발된 유리에 대한 점도 분포 최적 영역을 도출하기 위해 먼저 유리조성에 일정비율의 알루미늄 금속을 혼합하여 전 기로를 이용하여 용융하였다. Table 2 의 혼합 시료로 개발 된 유리의 점도 분포를 측정한 결과 Fig. 1 과 같이 나타났다. 그림에서 $\mathrm{A}$ 는 HEPA 및 medium 필터의 유리섬유와 알루 미늄이 1:1로 혼합된 시료에서 알루미늄 함량은 약 $67 \mathrm{wt} \%$ 를 차지하고 있으며, B는 혼합시료 A에서 알루미늄 함량이 $10 \%$ 적게 혼합된 시료의 분포를 보여주고 있다. 이들 시료 는 $1,100^{\circ} \mathrm{C}$ 이상에서 점도의 상한치인 100 poise 이하를 만 족 하는 것으로 분석되었다. 각각의 유리조성 모두 CCIM 운 전온도인 $1,150^{\circ} \mathrm{C}$ 에서 측정치와 계산치 점도가 잘 일치 하 는 것으로 평가되었다.

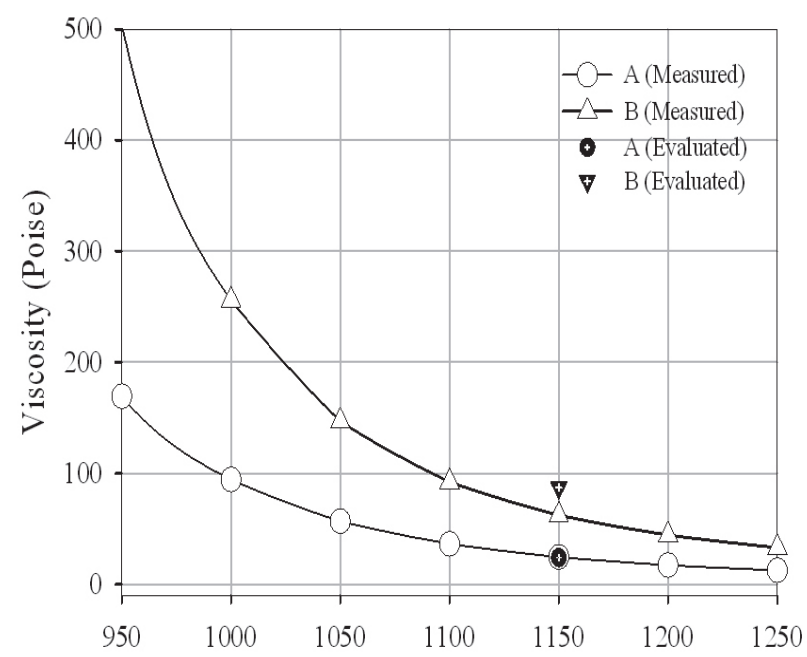

Fig 1. Viscosity Distribution for Glasses of Sample Mixed with Glass Fiberand $\mathrm{Al}$ (A: Al content is $67.4 \mathrm{wt} \%$ on sample, $\mathrm{B}$ : Al content is 59.4 wt\% on sample) 


\section{3. 결과 및 논의}

\section{1 유리조성 개발}

개발된 유리조성을 이용하여 용융시험을 한 결과, 필터 투입중량 $35 \mathrm{wt} \%$ 에서 용융 점도는 47 poise 이하 전기전 도도는 $0.45 \mathrm{~S} / \mathrm{cm}$, PCT (Product Consistency Test)는 기 준유리의 기준값 $1 / 2$ 이하로 나타났다. 이것은 컴퓨터코드 (GlassForm)로 계산된 값에 비해 전반적으로 높게 나타났 다. 따라서 알루미늄 금속이 함유된 폐기물의 유리조성 개 발에는 실험값과의 편차 발생 원인을 추가로 분석할 필요 가 있다. 폐기물 투입률 (Waste Loading)을 높이기 위해 필터 투입비를 $45 \mathrm{wt} \%$ 로 하고, 유리프릿에 $\mathrm{Na}_{2} \mathrm{O}$ 를 추가 하여 용융물 상태를 분석한 결과 코드 계산과는 달리 용융 물 점도는 높았으며 배출 또한 원활하지 못하였다. 그러나 $\mathrm{B}_{2} \mathrm{O}_{3}+\mathrm{Na}_{2} \mathrm{O}$ 를 적절한 비율로 혼합하여 추가한 경우 용융물 이 배출 가능한 유동상태를 보여주었다. 따라서 폐기물 감 용과 낮은 점도를 위해 필터에 다수의 첨가제 $\left(\mathrm{B}_{2} \mathrm{O}_{3}+\mathrm{Na}_{2} \mathrm{O}\right.$ $\left.+\mathrm{Li}_{2} \mathrm{O}\right)$ 를 적절하게 혼합하여 유리프릿을 개발할 필요가 있 다. 따라서 필터 유리화에서 개발된 유리조성과 용융시험 분석자료는 향후 국내·외 관련 폐기물 유리화를 위한 중 요한 기초자료로 활용될 예정이다. 특히 알루미늄 금속에 대한 처리해법을 마련할 뿐만 아니라 장기적으로 안정적인 처분문제도 해결할 것으로 기대한다.

\section{$3.2 \mathrm{~A} 1$ 용융}

알루미늄의 용융 특성을 분석하기 위해 $100 \mathrm{~g}$ 의 알루미 늄 호일 (foil)을 시료로 준비하였다. 알루미늄에 대한 용융

Table 4. Oxide Compositions of Final Glass for Filter Waste.

\begin{tabular}{lrcc}
\hline \multirow{2}{*}{ xxide } & HVAC35A & HVAC35B & HVAC35C \\
\cline { 2 - 4 } & \multicolumn{3}{c}{ Candidate Glasses } \\
\hline $\mathrm{Li}_{2} \mathrm{O}$ & 1.4 & 5.1 & 2.7 \\
\hline $\mathrm{B}_{2} \mathrm{O}_{3}$ & 32.0 & 34.2 & 26.8 \\
\hline $\mathrm{Na}_{2} \mathrm{O}$ & 21.9 & 13.5 & 24.0 \\
\hline $\mathrm{Al}_{2} \mathrm{O}_{3}$ & 24.6 & 24.8 & 24.2 \\
\hline $\mathrm{SiO}_{2}$ & 17.9 & 20.6 & 15.9 \\
\hline $\mathrm{K}_{2} \mathrm{O}$ & 0.3 & 0.3 & 0.3 \\
\hline $\mathrm{CaO}$ & 1.0 & 1.0 & 1.0 \\
\hline $\mathrm{ZnO}$ & 0.3 & 0.3 & 0.3 \\
\hline Other & 0.6 & 0.2 & 4.8 \\
\hline
\end{tabular}

*) HVAC35A : HVAC (Mixed HEPA and Medium) 35 (Waste Loading 35 wt\%) A (Normal Amount of Al on Mixing 1:1 of Glass Fiber and Al)
상태를 파악하기 위해, 알루미늄만을 도가니에 준비한 후 전기로에서 설정온도까지 상승 시킨 후 $1,150^{\circ} \mathrm{C}$ 에서 1 시간 가량 온도를 지속하였다. Fig. 2는 알루미늄 호일에 대한 용 융상태 후를 보여주고 있다. 실제 알루미늄 폐기물이 필터 와 함께 파쇄의 전처리 과정을 거친 후 펠렛화 공정을 고려 하여, 향후 펠렛에 포함되는 알루미늄의 양에 따른 용융상 태를 고려해 보기로 하였다. 먼저 알루미늄 호일을 잘게 잘 라서 용융시킨 경우와 덩어리로 뭉쳐진 상태의 용융 결과를 보기위해 그림과 같이 시료를 준비하였다. 전기로에서 용융 시킨 결과 잘게 자른 알루미늄 시료의 경우 재만 발생되었 으나, 덩어리 상태로 투입한 경우에는 덩어리 크기에 관계 없이 금속이 생성되는 것을 확인하였다.

$\mathrm{HVAC}$ 필터에 대해 개발한 유리조성은 알루미늄을 단독으 로 용융하는 경우와 필터를 용융하는 경우에 대해 수행하였 다. 알루미늄을 단독으로 처리하기 위해 개발된 유리를 알루 미늄과 혼합하여 Fig. 3 과 같이 시료를 준비한후 전기로에서 용융하였다. 유리 프릿에 알루미늄 혼합률은 $20 \mathrm{wt} \%$ 내외에 서 중량비를 달리하여 혼합한 후 실험한 결과 최대 $30 \mathrm{wt} \%$ 에 서도 잘 부어짐을 확인할 수 있었다. 하지만, 알루미늄 금속 함량을 $50 \mathrm{wt} \%$ 이상으로 하여 용융한 결과 최종 고화체에 소 량의 금속이 발생 하였다. 따라서 알루미늄 금속 폐기물을 단 독으로 유리화하기 위해서는 적절한 함량의 폐기물을 혼합하 여 처리할 필요가 있음을 확인하였다.

$\mathrm{CCIM}$ 을 이용한 $1,150^{\circ} \mathrm{C}$ 환경에서 고품질의 최종 유리고 화체를 생성할 수 있는지를 평가하기 위해, 필터와 유리프

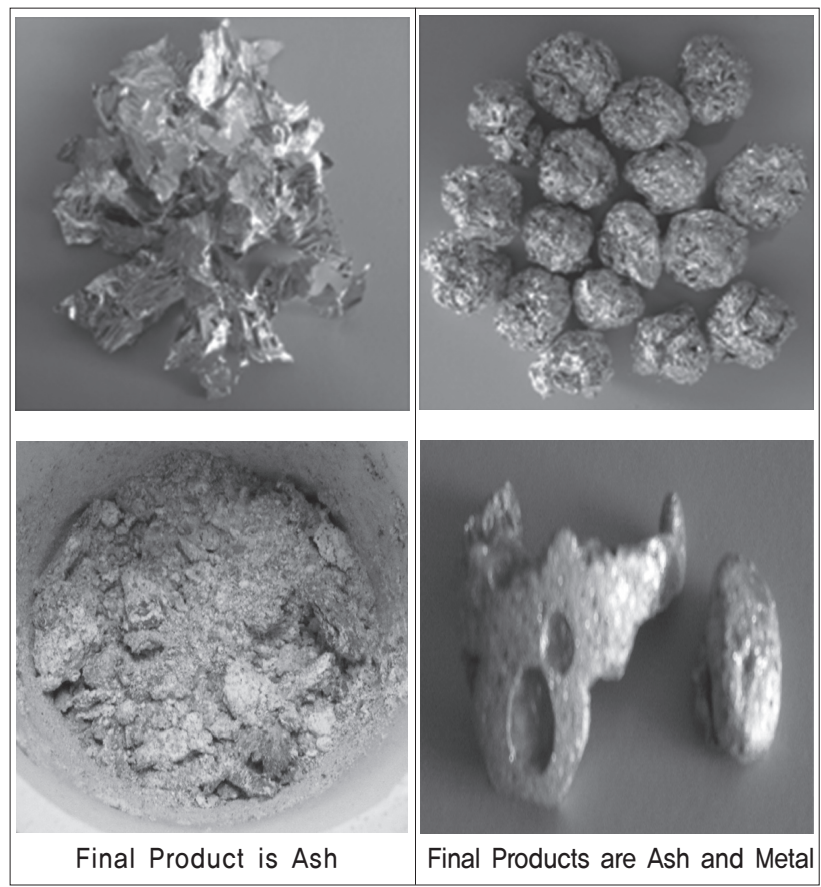

Fig. 2. Products of Al Material Melted at $1,150^{\circ} \mathrm{C}$. 


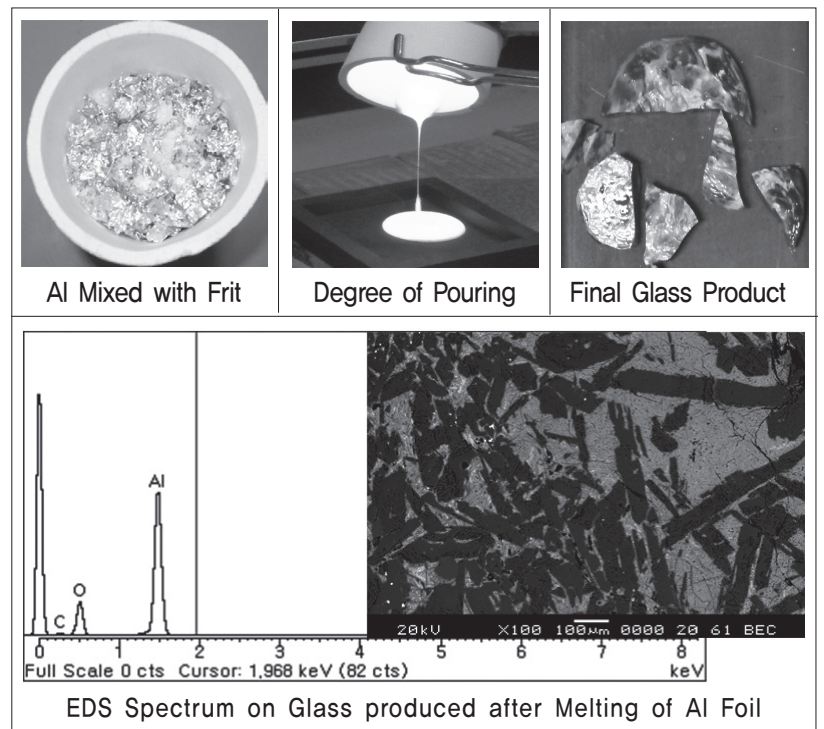

Fig. 3. Melting Results for Al Foil.

릿 (frit)을 혼합한 후 점토 도가니 (clay crucible)에 옮겨 담 아 $\mathrm{MoSi}_{2}$ 발열체 전기로를 이용하여 $1,150^{\circ} \mathrm{C}$ 에서 1 2시간 동안 가열한 다음 유리고화체를 제조하였다. 코드분석에서 필터용 유리프릿의 점도는 유리섬유와 혼합되는 알루미늄 함량이 최대 $75 \mathrm{wt} \%$ 에서도 용융 점도 범위 이내로 나타남 을 확인하였으나, 실제로 용융물을 흑연 몰드에 부었을 때 배출이 잘 되지 않았다. 또한 유리고화체의 전기전도도 측 정을 위해서 알루미나 도가니에 전기전도도를 측정하고자 하는 유리를 넣고 측정온도까지 온도를 맞춘 후 $15 \mathrm{~mm}$ 간 격으로 고정된 두개의 백금 $(\mathrm{Pt})$ 전극을 유리용탕 $10 \mathrm{~mm}$ 깊이까지 삽입하였다. 여기에 주파수 $1 \mathrm{kHz}$ 로 고정된 LCR meter를 이용하여 용융유리의 저항을 측정하였고 이 값을 전기전도도로 환산하였다. 온도 $915 \sim 1,165^{\circ} \mathrm{C}$ 범위에서 측 정한 전기전도도 값을 이용하여 $1,000 \sim 1,300^{\circ} \mathrm{C}$ 범위에서 전기전도도 값으로 계산한 결과, 유리는 측정온도 구간에 서 유리의 용융상태의 전기전도도 요구치 $(0.1 \sim 1.0 \mathrm{~S} / \mathrm{cm})$ 를 만족하였다.

\section{3 후보유리 용융 특성}

실제 폐기물을 처리할 경우, 필터 폐기물 투입과 동시에 조 성유리가 첨가되기 때문에 이 경우를 고려한 알루미늄 용 융 조건을 실험하였다. 따라서 알루미늄의 양에 따른 금속 발생여부를 확인하기 위해 알루미늄에 조성유리의 성분을 첨가한 후 용융실험을 수행하였다. 실제 폐기물 용융에서 는 폐기물에 조성유리가 첨가되어 대부분의 폐기물 조성 은 산화물 형태로 형성되며 마찬가지로 알루미늄은 $\mathrm{Al}_{2} \mathrm{O}_{3}$
화 되어 유리성분으로 형성되게 된다. Fig. 4 와 같이 유리 조성과 혼합된 필터에 대한 용융의 경우, 그림에서 첫 번째 는 필터폐기물에 유리조성 투입량을 달리하여 혼합한 경우 이며, 각 시료 하단방향으로 두 번째는 도가니에서 용융상 태를 보여주고 있다. 설정 온도에서 일정시간 용융시킨 후 각 시료 하단 세 번째 그림과 같이 실제 배출 정도를 확인한 결과 두 경우 모두 저점도 상태임을 확인하였으며, 수월하 게 따를 수 있는 것으로 확인하였다. 각 시료의 마지막 네

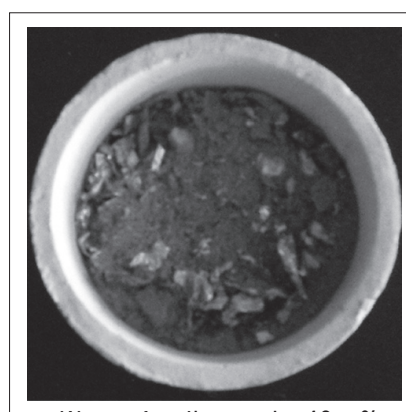

Waste feeding ratio $40 w t \%$

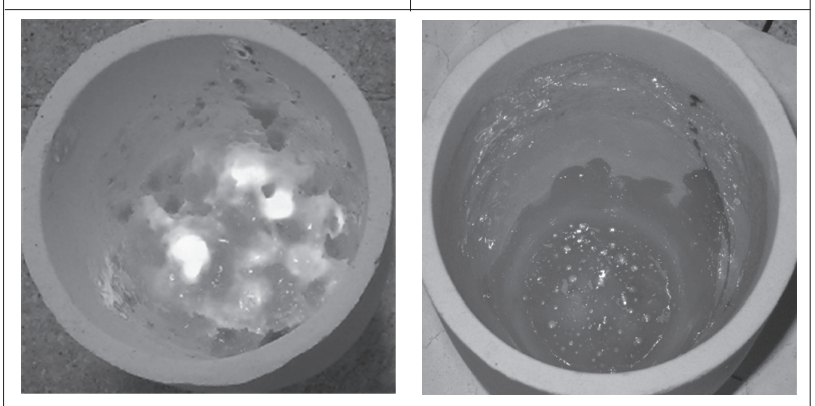

Melting state in crucible

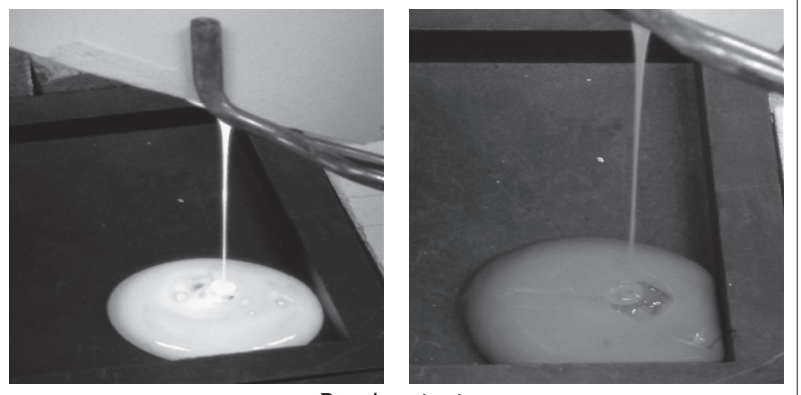

Pouring test

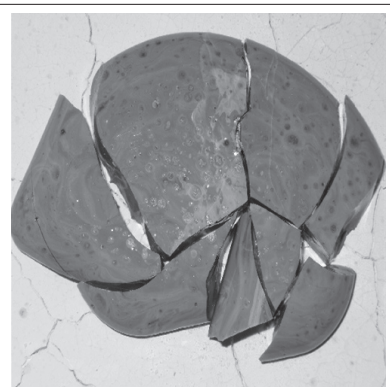

Final glass product for waste feeding ratio $40 w t \%$

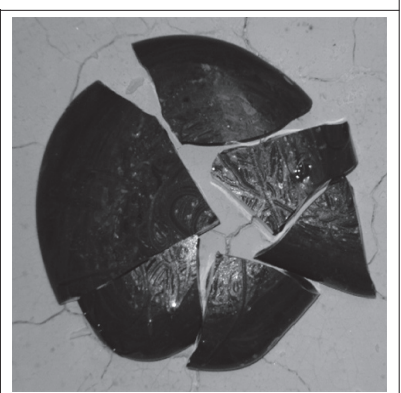

Final glass product for waste feeding ratio $35 w t \%$
Fig. 4. Final Products of Filter. 


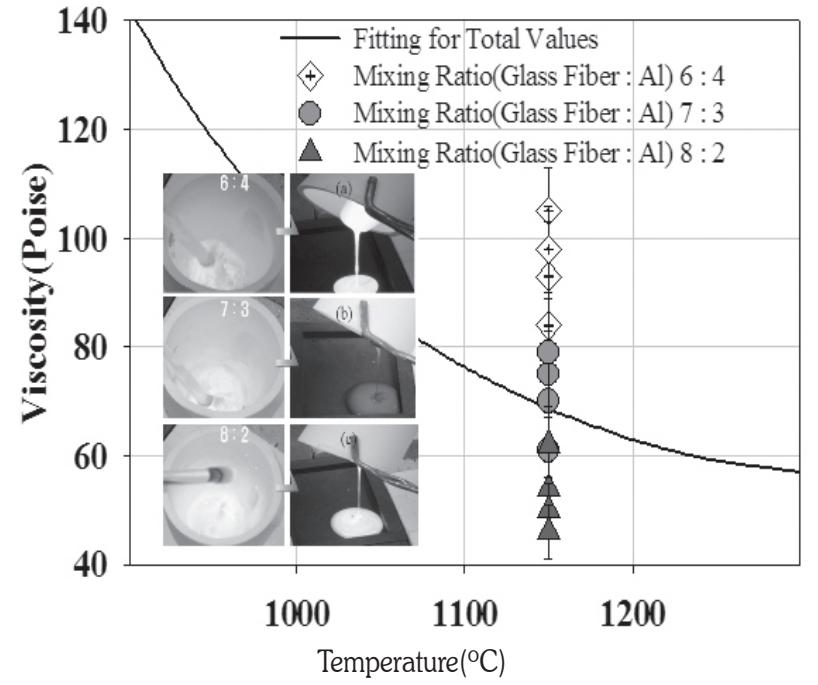

Fig. 5. Viscosity of Glass Melt for Filter and Test of Melting Pouring. Mixing Ratio of (a) 6:4 (b) 7:3 and (C) 8:2 for Glass Fiber and Al.

번째는 최종 생성된 유리고화체로서, 고품질의 유리가 생성 됨을 확인하였으며, 알루미늄 성분에 의한 금속은 형성되지 않음을 확인하였다.

실제 폐기물 용융후의 겉보기 점도 상태는 Fig. 4 와 같으 며, 점도측정기를 이용한 유리섬유와 알루미늄이 일정비 율 혼합된 필터의 점도 분포는 Fig. 5와 같이 나타났다. 폐 기물에 혼합되는 알루미늄 중량비가 높을수록 점도가 높 아짐을 확인할 수 있었으며, 실험에서 얻은 값들은 알루미 늄 금속 혼합량이 적을수록 낮은 점도 분포를 보이는 것으 로 나타났다. 따라서 용융물이 로에서 원활하게 배출되기 위해서는 유리섬유에 혼합되는 알루미늄량이 적을수록 낮 은 점도를 유지할 수 있으나 이 경우 폐기물 감량 효과가 적을 수 있다. 그림에서 좌측의 도가니 용융 형상은 알루 미늄 금속의 혼합율별 점도의 실제 따름 (pouring) 현상 을 확인한 것이다. 점도에 대한 이론 및 실험값과 마찬가 지로 실제 액체 유동 상태에서도 알루미늄 혼합이 많을수 록 점도가 높아짐을 확인할 수 있었다.

침출시험은 고화체의 안정성 및 균일성 등을 측정하기 위한 견고성 시험으로서 유리고화체내 원소들의 침출거

Table 5. Comparison of Leaching Test Results for Candidate Glass and Standard Glass.

\begin{tabular}{|c|c|c|c|c|}
\hline Element & HVAC35A & HVAC35B & HVAC35C & SRL-EA*) \\
\hline $\mathrm{Si}\left(\mathrm{g} / \mathrm{m}^{2}\right)$ & 0.41 & 0.31 & 0.42 & $<2.24$ \\
\hline $\mathrm{B}\left(\mathrm{g} / \mathrm{m}^{2}\right)$ & 0.46 & 0.71 & 2.13 & $<9.94$ \\
\hline $\mathrm{Na}\left(\mathrm{g} / \mathrm{m}^{2}\right)$ & 0.32 & 0.75 & 1.87 & $<7.43$ \\
\hline $\mathrm{Li}\left(\mathrm{g} / \mathrm{m}^{2}\right)$ & 0.55 & 0.67 & 2.14 & $<4.93$ \\
\hline
\end{tabular}

동을 기준 (benchmark) 유리와 비교하는데 이용된다. 본 연구에서는 대상폐기물의 유리조성체에 대해 PCT를 수행하였다. PCT를 수행하기 위해 유리고화체를 파쇄한 후 $150 \mu \mathrm{m}$ (100 mesh) 크기의 입도크기 분석용 Seive를 통과시키고 $70 \mu \mathrm{m}(200 \mathrm{mesh})$ 크기의 Seive에서 걸러진 유리 $5 \mathrm{~g}$ 정도를 취한 다음 스테인레스강 (SUS 304L) 용 기에 넣고 유리 무게의 10 배에 해당하는 ASTM Type I (미국표준협회, 원자결합 등에 사용하는 초순수 등급) 탈 이온수로 채운 후 밀봉하였다. 이 경우 유리의 표면적과 침출수의 체적비는 $2,000 \mathrm{~m}^{-1}$ 이다. 미리 $90^{\circ} \mathrm{C}$ 로 예열된 오븐에 넣고 7일이 지난 후 꺼내어 침출수 중 $1 \mathrm{ml}$ 를 추 출해 $1 \% \mathrm{HNO}_{3} 20 \mathrm{ml}$ 용액이 담긴 바이얼에 담아 분석 하였다. 유리고화체로부터 침출되어 나온 원소들의 침출 율은 기준유리와 비교하였다. 사용 후 필터에 대한 후보 유리의 침출수 $\mathrm{pH}$ 는 9.8 11.3으로 나타났다. 유리고화 체에 대한 침출시험 결과는 Table 5와 같다. 침출용액을 ICP-AES로 분석 한 후 침출률 (Leach Rate)을 계산한 결 과 각 원소에 대한 침출률은 기준유리에 비해 현저히 낮 은 것으로 분석되었다. 따라서 본 연구로부터 개발된 유 리조성을 이용하여 유리화 할 경우 고 품질의 유리고화체 가 생성됨을 확인하였다.

사용 후 필터에 대한 유리고화체를 주사현미경 (SEM, JSM-5600)을 이용하여 분석한 결과, 이차상이 없는 균질한 상태로 나타났다. 사용 후 필터에 대한 에너지분산형분광 기 (EDS) 성분 분석결과 $\mathrm{SiO}_{2}+\mathrm{Al}_{2} \mathrm{O}_{3}+\mathrm{Na}_{2} \mathrm{O}$ 가 $95 \mathrm{wt} \%$ 이상 분포하였다. 필터에서 생성된 유리는 산화물 함량에 따라 녹청색이나 회색을 띄었으며 알루미늄이 결정형태로 침전 됨이 없이 완전 산화되어 유리구조속으로 모두 용해되어 들 어간 것으로 확인되었다.

\section{4. 결 론}

원전에서 발생되는 방사성폐기물 중 유리섬유와 알루미 늄이 혼합된 필터를 유리화하기 위한 타당성 연구를 위해 유리조성 개발과 유리고화체 특성 평가를 수행하였다. 알 루미늄 금속만 용융할 경우 붕규산 유리성분에서 잘 용융되 는 것으로 나타났으나, 로의 운전변수 중 중요한 점도를 맞 추기 위해서는 첨가제 $\left(\mathrm{Na}_{2} \mathrm{O}\right.$ 등)가 추가로 필요한 것으로 평가되었다. 개발된 유리조성의 산화물 분포는 $\mathrm{B}_{2} \mathrm{O}_{3}$ 의 경 우 $20 \mathrm{wt} \%$ 내외, $\mathrm{Na}_{2} \mathrm{O}$ 의 경우 $15 \mathrm{wt} \%$ 내외, 그리고 $\mathrm{SiO}_{2}$ 의 경우 $45 \mathrm{wt} \%$ 내외가 적절한 것으로 나타났다. 이 경우 알루 미늄 금속은 $1,150^{\circ} \mathrm{C}$ 유리용탕 환경에서 산화물 형태로 되 어 금속으로 침전되지 않고 유리구조속에 균질하게 분포 하 
는 것으로 나타났다. 그러나 배출시 용융물의 점도가 급격 히 높아져 배출이 잘되지 않는 것으로 나타났다. 알루미늄 단독 용융보다는 유리섬유와 알루미늄 금속이 혼합된 필터 자체를 유리화 하기 위해 필터 투입량 $40 \mathrm{wt} \%$ 이하에서 유 리조성을 개발하였다. 유리섬유와 혼합되는 알루미늄 금속 함량이 $70 \mathrm{wt} \%$ 이상 차지하는 폐기물의 경우 용융물의 낮 은 점도를 위해 유리프릿에 대한 폐기물 투입량을 $35 \mathrm{wt} \%$ 내외가 되도록 개발하였다. 이경우 최적의 용융상태를 유지 하는 것으로 나타났으며 최종고화체 또한 품질이 양호한 것 으로 확인되었다.

필터의 경우 $\mathrm{SiO}_{2}$ 와 $\mathrm{Al}_{2} \mathrm{O}_{3}$ 양이 대부분을 차지하기 때문에 폐기물 투입량이 현저하게 낮으며 용융 상태의 점도와 전기 전도도 또한 높게 나타났다. 유리화 공정 중 발생한 유리고 화체는 처분장 환경에서 물리·화학 및 방사선적 관점에서 안정해야 한다. 다른 많은 재료 가운데서도 유리가 방사성 폐기물의 처리 매질로 선정된 가장 큰 이유는 방사성 물질 을 환경에 누출시키지 않고 장기간 보존하는 화학적 견고성 이 뛰어나기 때문이다. 따라서 알루미늄 금속이 함유된 필 터에 대한 유리조성을 국제적으로 인증된 침출시험법을 이 용한 시험 결과, 유리고화체의 침출성은 기준유리(SRL-EA) 보다 우수한 것으로 나타났다.

\section{REFERENCES}

[1] Technical Report "Waste Vitrification Systems Lessons Learned", DOE Report, pp.21-33 (1999).

[2] W. Baehr, "Industral Vitrification Processes for HighLevel Liquid Waste Solutions", IAEA Bulletin pp.4346 (1989); CEA(http://www.cea.fr/var), IRSS (http:// www.irss-usa.org)

[3] A. Aoshima, K. Tanaka, Easte Treatment Experience, Future Plans in Tokai Reprocessing Plant, WM05 Conference, February 27-March 3, 2005, Tucson, AZ

[4] Charles Jensen, EPRI International Low-Level Waste Conference, "The Role of Advanced Polymer Solidification in a Comprehensive Plan for Handling, Storing and Disposing of Class B \& C Resins and Filters", June 24-26, 2008.

[5] Hyun-Je Cho, Deuk-Man Kim and Jong-Kil Park, "Feasibility Study on Vitrification of Concentrated Boric Acid Waste", J. of the Korean Radioactive
Waste Society, 8(2), pp.143-150 (2010).

[6] Hyun-Je Cho, Deuk-Man Kim and Jong-Kil Park, "Study on Pre-treatment Method for Vitrification of Concentrated Wastes", J. of the Korean Radioactive Waste Society, 8(3), pp.221-227 (2010). 